American Journal of Applied Sciences 6 (10): 1776-1780, 2009

ISSN 1546-9239

(C) 2009 Science Publications

\title{
Color Doppler Ultrasound Indices in Endometriotic Cysts
}

\author{
${ }^{1}$ Parisa Hajialioghlo, ${ }^{1}$ Fatemeh Ghatresamani, ${ }^{2,3}$ Nariman Nezami and ${ }^{1}$ Narges Sobhani \\ ${ }^{1}$ Department of Radiology, Tabriz University (Medical Sciences), Tabriz, Iran \\ ${ }^{2}$ Young Researchers Club, Tabriz Islamic Azad University, Tabriz, Iran \\ ${ }^{3}$ Drug Applied Research Center, Tabriz University (Medical Sciences), Tabriz, Iran
}

\begin{abstract}
Problem statement: There have been considerable interests on using non-invasive techniques to detect endometriosis. A few studies were evaluated the Doppler ultrasound findings of endometriosis. This study aimed to characterize the grayscale and Doppler ultrasound findings of endometriosis. Approach: During present prospective study, gray scale and Doppler ultrasound findings of 37 women with final diagnosis of endometriosis were evaluated. Patients with probable diagnosis of endometriosis underwent conventional transvaginal and color Doppler assessment. After laparascopic confirmation of endometriosis, gray scale and color Doppler ultrasonographic data of patients considered for analysis. Results: Finally data of 37 subjects' data with suspected endometriosis was analyzed. Twenty nine of lesions were endometriosis, five hydrosalpinx, four paraovarian adhesion cysts and one peritoneal inclusion cyst according to laparoscopic exploration. Out of 29 endometriotic cysts, flow was detected in $58.62 \%$. The mean of RI and PI were $0.67 \pm 0.15$ (0.46-1.00) and 1.49 \pm 0.85 (0.66-3.11), respectively. Conclusion: In our experience, transvaginal sonography with color Doppler interrogation is a useful technique in the diagnosis of pathologic ovarian conditions, including cystic endometriosis.
\end{abstract}

Key words: Endometriosis, doppler ultrasound, resistance index, pulsatility index

\section{INTRODUCTION}

Endometriosis is defined by the presence of endometrial glands outside the uterus ${ }^{[1,2]}$. Endometriosis usually presents with pain such as period pain (dysmenorrhea), pain on intercourse (dyspareunia), or non-menstrual pelvic pain. It may also be found incidentally at operations such as sterilization, or during investigation for infertility. Symptoms do not necessarily correlate with the extent of disease. Endometriosis can be detected in up to $15 \%$ of women, with a peak frequency between 30 and 35 years of age $\mathrm{e}^{[3,4]}$.

Laparoscopy and laparotomy remain the gold standard for diagnosis and staging against which other modalities are judged ${ }^{[5-7]}$. Since these procedures are associated with some major and minor complications, there have been considerable interests on using noninvasive techniques, including ultrasound, CT, MRI and tumor markers to detect endometriosis.

Some authors believe that the diagnosis of endometriosis on base of ultrasound appearance is a reliable method ${ }^{[8]}$. However, there are finger count studies evaluated the Doppler ultrasound findings of endometriosis. This study aimed to characterize the grayscale and Doppler ultrasound findings of endometriosis.

\section{MATERIALS AND METHODS}

During present prospective study from May 2007 to August 2008, gray scale and Doppler ultrasound findings of 37 women with final diagnosis of endometriosis were evaluated. Patients with infertility problems, pelvis pain, accidentally found adnexal mass during clinical or gray scale evaluation and a persistent cyst after 6 weeks follow up were referred to Tabriz Alzahra Obstetrics and Gynecology Hospital for further assessment and make final diagnosis by laparoscopy.

All patients gave informed consent. Study protocol was supervised and approved by the ethic committee of Tabriz University of Medical Sciences (TUMS) which is in compliance with the Helsinki Declaration.

Prior to laparoscopy, patients with probable diagnosis of endometriosis underwent conventional transvaginal and color Doppler assessment by EUB 525 ultrasound machine (Hitachi Medical Corp, Tokyo,

Corresponding Author: Nariman Nezami, Clinical Pharmacy Laboratory, Drug Applied Research Center,

Tabriz University (Medical Sciences), Pashmineh, Postal code: 5165665811, Daneshagh Street, Tabriz, Eastern Azerbaijan, Iran Tel: +984113311147/+989141130560 Fax: +984113363231 
Japan) using $5 \mathrm{MHz}$ transvaginal transducer. Ultrasound evaluation was performed 1 and 2 weeks before to surgery during the proliferative phase of menstrual cycle (4th-8th day of manesturation phase). Ultrasound study lasted 20-30 min for each patient.

After determining masses morphology, pulsed Doppler was used to interrogate each color signal identified and a Flow-Velocity Waveform (FVW) was obtained. Only arterial FVWs were processed. The Pulsatility Index (PI) and Resistance Index (RI) were electronically computed. When multiple signals were obtained, the lowest PI and RI were used for analytical purposes. RI and PI were calculated from the Doppler spectra using the following relations:

RI = Peak systolic velocity-end diastolic velocity/peak systolic velocity

PI = Peak systolic velocity-end diastolic velocity/mean velocity

Sample volume was set at a $1.2-2 \mathrm{~mm}$ width. The high-pass filter was set at $50 \mathrm{~Hz}$. The spatial peak temporal average intensity was $<80 \mathrm{~mW} \mathrm{~cm}^{-2}$ in Bmode, power-Doppler and pulsed Doppler modes. The pulse-repetition frequency was set at $1.5-25 \mathrm{kHz}$. One examiner $(\mathrm{PH})$, who was blinded to patient complaints in order to avoid biased assessments of vascularity, performed all examinations.

After laparascopic confirmation of endometriosis, gray scale and Doppler ultrasonographic data of patients considered for analysis.

Statistical analyses were performed by SPSS software package for windows version 13.0 (SPSS, Chicago, USA). Results are presented as mean \pm Standard Deviation (SD). Statistical significance between groups of evaluation was estimated using one-way repeated measures ANOVA/Friedman, Fisher's exact or Chi-square, Independent Samples t-test/ Man Whitney U tests. Also correlation of variables was studied by Pearson correlation. The results were considered significant when the p-value was less than 0.05 .

\section{RESULTS}

Finally data of 37 subjects' data with suspected endometriosis was analyzed. Twenty nine of lesions were endometriosis, five hydrosalpinx, four paraovarian adhesion cysts and one peritoneal inclusion cyst according to laparoscopic exploration. The mean age of subjects was 30.55 \pm 5.54 years (ranged 16-43 years). Figure 1 shows prevalence of primary chief compliant in studied population. Infertility and pelvic pain are two common complaints of endometriosis in this study.

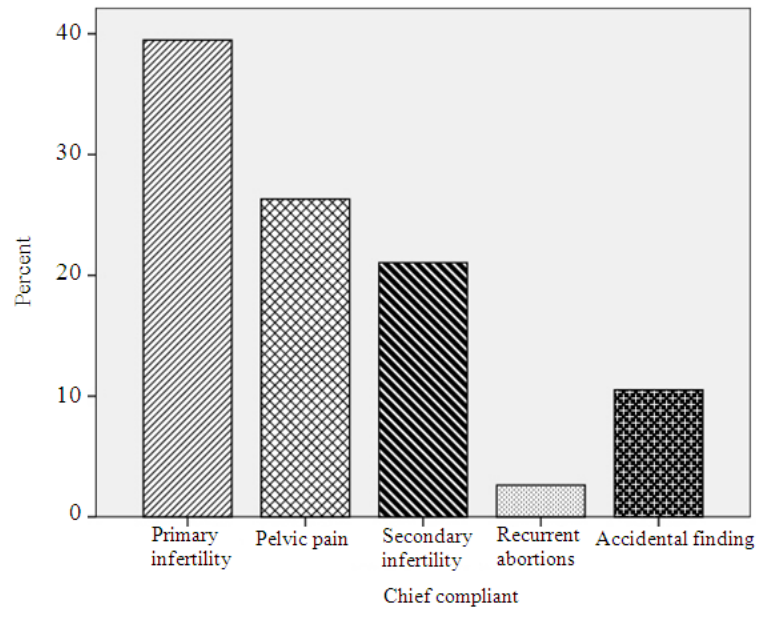

Fig. 1: Frequency of chief complaints in studied population

Table 1: Gray scale appearances of endometriosis

\begin{tabular}{ll}
\hline Appearance in gray scale ultrasound study & $\begin{array}{l}\text { No. of } \\
\text { cysts }\end{array}$ \\
\hline $\begin{array}{l}\text { A round, multicystic mass with internal low-level echoes } \\
\text { associated with solid (Typical view of endometriosis which } \\
\text { is shown in Fig. 2) }\end{array}$ & 24 \\
$\begin{array}{l}\text { A cystic mass with thick wall having diffuse to moderately high } \\
\text { level echoes tat mimic solid mass, but compression of mass with } \\
\text { the probe demonstrate internal echoes move slowly }\end{array}$ & 6 \\
$\begin{array}{l}\text { A heterogenous mass with cystic appearance and solid } \\
\text { hypoechoes }\end{array}$ & 1 \\
$\begin{array}{l}\text { A big cystic mass without wall thickness, irregularity and } \\
\text { septation; a persistent cyst after 6 weeks follow up (Fig. 3) }\end{array}$ & 2 \\
A cystic mass with smooth and irregular wall & 6 \\
\hline
\end{tabular}

Various gray scale appearance of endometriosis and its prevalence were listed in Table 1. The mean volume of cysts was $89.11 \pm 150.80 \mathrm{~mL}$ (ranged 8$859 \mathrm{~mL})$. Six (15.38\%) cysts had thick wall and reminder showed smooth wall. Internal surface of 34 $(87.17 \%)$ cysts were normal, while remainder 5 cysts internal surface were irregular. Intracystic septa were detected in $4(10.25 \%)$ cysts; three in endometriotic cyst and one in other type. The anechoic pattern was not found in Endometriotic cysts, while was demonstrated in one subject with other types of cyst. Internal diffuse echoes were only shown in three other types of cysts. One of endometriotic cyst had solid pattern. Hetergeneous pattern was demonstrated in one endometriotic cyst. Among from 29 endometriotic cysts, 26 had low level echoes and reminder three cysts showed moderate to high level echoes.

In $17(43.59 \%)$ subjects, cyst was avascular. Out of 29 endometriotic cysts, flow was detected in $58.62 \%$. The mean of RI and PI were $0.69 \pm 0.18$ (0.25-1.00) and $1.52 \pm 0.76(0.66-3.11)$, respectively. No flow was detected inside the cyst. Out of 39 cysts, 
Am. J. Applied Sci., 6 (10): 1776-1780, 2009

Table 2: Blood flow determination rate and Doppler indices in cases of endometriosis and other detected cases.

\begin{tabular}{|c|c|c|c|c|c|c|c|c|}
\hline \multirow[b]{2}{*}{ Laparoscopic finding } & \multirow[b]{2}{*}{ No } & \multirow{2}{*}{$\begin{array}{l}\text { Detection of } \\
\text { blood flow }\end{array}$} & \multicolumn{3}{|l|}{ RI } & \multicolumn{3}{|l|}{ PI } \\
\hline & & & Mean & $\mathrm{SD}$ & Range & Mean & $\mathrm{SD}$ & Range \\
\hline Endometriosis & 29 & 17 & 0.67 & 0.15 & $0.51-1$ & 1.49 & 0.85 & $0.66-3.11$ \\
\hline Hydrosalpinx & 5 & 5 & 0.75 & 0.29 & $0.25-0.95$ & 1.60 & 0.34 & $1.21-1.90$ \\
\hline Paraovarian adhesion cyst & 4 & 0 & - & - & - & - & - & - \\
\hline Peritoneal inclusion cyst & 1 & 0 & - & - & - & - & - & - \\
\hline
\end{tabular}

RI: Resistance Index, PI: Pulsatility Index, SD: Standard Deviation

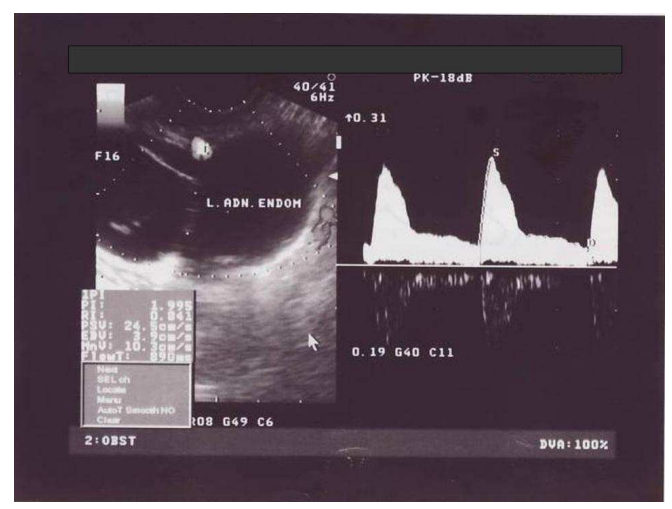

Fig. 2: Typical presentation of endometriosis in gray scale Doppler evaluation
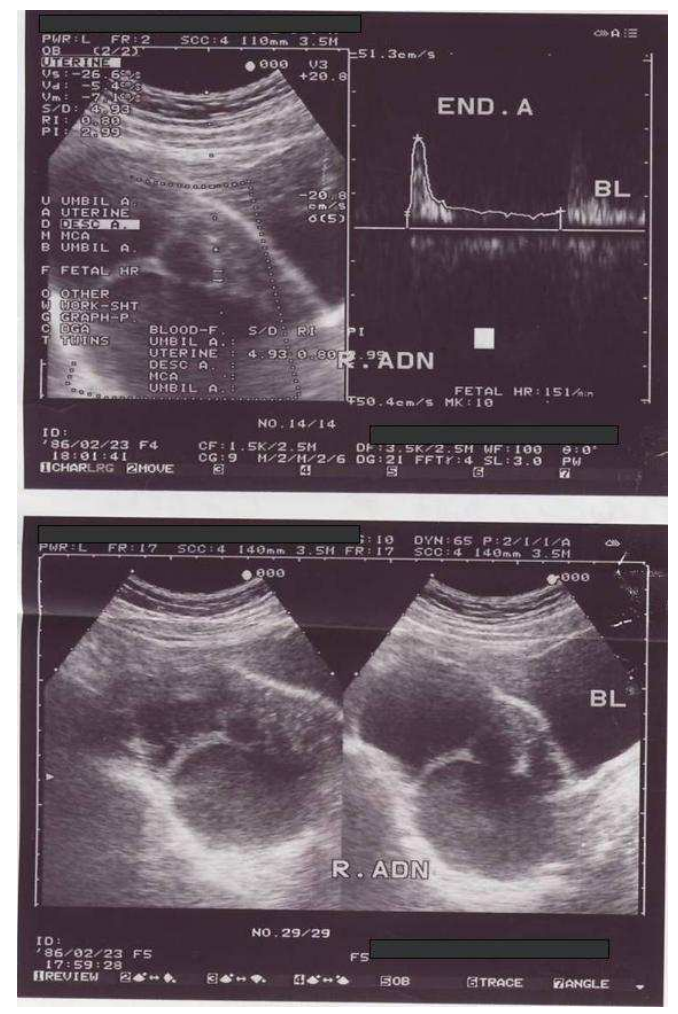

Fig. 3: Another common presentation of endometriosis in gray scale Doppler evaluation blood flow was not detected in four paraovarian adhesion cysts and one peritoneal inclusion cyst. Blood flow determination rate and Doppler indices demonstrated in Table 2 according to laparoscopic diagnosis of cysts.

There was a direct linear correlation between RI and PI in endometriotci cyst $(\mathrm{p}<0.001, \mathrm{r}=+0.771)$, while such relation was not found between RI and PI of other types of pelvic cysts $(\mathrm{p}=0.192)$.

\section{DISCUSSION}

The accurate diagnosis of EC is important to avoid unnecessary surgical procedures. Endometriotic cysts may be confused with hemorrhagic functional cysts and, if the patient has a poor response to medical treatment, the cysts should be removed surgically.

A few publications have attempted to define the mean RI and PI values for blood vessels in endometriomsis to differentiate this type of mass from other pelvic masses ${ }^{[9-12]}$. The endometriomsis was grouped as benign pelvic mass and exploring the range of values (for RI and PI) and description of the vascular pattern during Doppler sonography of endometriomsis was the aim of few studies.

The homogeneous filling of the cyst with low-level echoes has been considered a helpful sign in the detection of endometriomsis during gray scale ultrasound evaluation ${ }^{[13-15]}$. However, this sonographic appearance of endometriomsis does not seem to be pathognomonic. We found this kind of pattern only in $61.54 \%$ of endometriotic cysts as well as in two hydrosalpinx cysts and in one peritoneal inclusion cyst. A similar percentage of fine septa or clear, anechoic sonographic fluid contents was found along with the typical appearance of the contents of the endometriomsis.

Actually, in all 17 cysts (58.62\%), endometriomsis showed only occasional separate vessels in the wall of the cyst where flow signals were seen. The remaining 12 cysts showed no blood flow. Endometriomsis do not appear as vascular cysts. These data are in agreement with those of ${ }^{[9,10,16]}$ who found blood flow in 71, 73 and $69 \%$ of endometriomsis, respectively. Despite the high 
rate of vascular presence in endometriosis reported by most of studies ${ }^{[17]}$ in the study with a big sample size showed that endometriosis is a lesion with less frequent vascularization $(30.6 \%)$. The blood vessel pattern seen by color Doppler was, however, described only by some authors. The mean RI in our study, 0.67 , was consistent with values previously published by Kurjak et $a l .^{[12]}(\mathrm{RI}=0.56)$, Timor-Tritsch et al. ${ }^{[9]}$ $(\mathrm{RI}=0.63), \quad$ Aleem et $a l .{ }^{[16]} \quad(\mathrm{RI}=0.59 \quad$ and Pascual et al. ${ }^{[17]}(\mathrm{RI}=0.63)$.

The mean PI of 1.49 in our population was in agreement with previously published values ${ }^{[10,11]}$, except Aleem et $a l .{ }^{[16]}$ reporting lower values of PI about 0.94 Tekay and Jouppila ${ }^{[10]}$ took the average PI values from several vessel locations around the cysts which might have included high-resistance vessels, thereby increasing the mean $\mathrm{p}$ value. However, the equivalent mean RI value of 0.40 published by these authors appears to be lower than the values seen in our cases. Due to the fact that PI and RI values are correlated, this discrepancy might be explained by differences in placement of the calipers during measurement of the end-diastolic flow. Different computer software used in ultrasound machines might be another factor which affects difference between our and Aleem et al. ${ }^{[16]}$ findings. Weiner et al.$^{[11]}$ described a PI value of $<1$ in one of ten cases of endometrioma. The PI range and mean were not mentioned. None of our studied endometriomsis showed an RI of less than 0.5 , like an Aleem et al. ${ }^{[16]}$ report. However, the PI values showed a greater range (0.66-3.11) and might be less useful in characterization of Doppler flow in endomelriomsis.

\section{CONCLUSION}

According to our results, three-fifths of endometriomsis have scattered vascularization by color Doppler sonography. RI and PI values do not overlap with RI and PI values of other benign lesions. The scattered vascularity, one feature of endometriomsis, may help to differentiate them from other lesions of dense vascular distribution. Vessel arrangement or vessel density plays a key role in the assessment of ovarian and other pelvic tumors ${ }^{[18]}$. Development of computer software to quantify blood vessel density during color Doppler evaluation might be more effective in the assessment of pelvic masses than Doppler flow indices alone. Our study is one of the rare studies described the vascular characteristics of endometriomsis. However, future studies with a large sample size of each type of pelvic mass are needed to substantiate these results further.
Transvaginal ultrasonography with color Doppler imaging is a useful tool for diagnosis of $\mathrm{EC}^{[8,19-21]}$. An accurate differential diagnosis avoids unnecessary surgical procedures, allowing, in young patients with EC, preservation of fertility through the use of laparoscopic surgery with ovarian conservation ${ }^{[22]}$.

\section{REFERENCES}

1. Brosens, I.A., 1997. Endometriosis-a disease because it is characterized by bleeding. Am. J. Obstet. Gynecol., 176: 263-267. http://www.ncbi.nlm.nih.gov/pubmed/9065165

2. Brosens, I.A., 1998. Endometriosis, current issues in diagnosis and medical management. J. Reprod. Med., 43: 281-286. http://cat.inist.fr/?aModele $=$ afficheN\&cpsidt $=2285883$

3. Preciado, R.R., C.J. Torres, J.A.Z. Montiel, J.C.M. Chequer, A.D. Manterola and L.A. Garcia, 2005. Incidence of endometriosis in infertile women: Clinical and laparoscopic characteristics. Ginecol. Obstet. Mex., 73: 471-476. http://www.ncbi.nlm.nih.gov/pubmed/16312272

4. Strathy, J.H., C.A. Molgaard, C.B. Coulam and L.J. Melton III, 1982. Endometriosis and infertility: A laparoscopic study of endometriosis among fertile and infertile women. Fertil. Steril., 38: 667-672. http://www.ncbi.nlm.nih.gov/pubmed/6216124

5. Spencer, J.A. and M.J. Weston, 2003. Imaging in endometriosis. Imaging, 15: 63-71. http://imaging.birjournals.org/cgi/content/abstract/ $15 / 2 / 63$

6. Ghattamaneni, S., M.J. Weston and J.A. Spencer, 2007. Imaging in endometriosis. Imaging, 19: 345-368. http://imaging.birjournals.org/cgi/content/abstract/ $19 / 4 / 345$

7. Osuga, Y., K. Koga, O. Tsutsumi, T. Yano, M. Maruyama, K. Kugu, M. Momoeda and Y. Taketani, 2002. Role of laparoscopy in the treatment of endometriosis-associated infertility. Gynecol. Obstet. Invest., 1: 33-39. DOI: 10.1159/000049422

8. Guerriero, S., S. Ajossa, A.M. Paoletti, V. Mais, M. Angiolucci and G.B. Melis., 1996. Tumor markers and transvaginal ultrasonography in the diagnosis of endometrioma. Obstet. Gynecol., 88: 403-407.

http://www.ncbi.nlm.nih.gov/pubmed/8752248

9. Timor-Tritsch, I.E., J.P. Lerner, A. Monteagudo and R. Santos, 1993. Transvaginal ultrasonographic characterization of ovarian masses by means of color flow-directed Doppler measurements and a morphologic scoring system. Am. J. Obstet. Gynecol., 168: 909-913. 
10. Tekay, A. and P. Jouppila, 1992. Validity of pulsatility and resistance indices in classification of adnexal tumors with transvaginal color Doppler ultrasound. Ultrasound Obstet. Gynecol., 2: 338-344. http://www.ncbi.nlm.nih.gov/pubmed/12796933

11. Weiner, Z., I. Thaler, D. Beck, S. Rottem, M. Deutsch and J.M. Brandes, 1992. Differentiating malignant from benign ovarian tumors with transvaginal color flow imaging. Obstet. Gynecol., 79: 159-162. http://www.ncbi.nlm.nih.gov/pubmed/1731278

12. Kurjak, A., H. Schulman, A. Sosic, I. Zalud and H. Shalan, 1992. Transvaginal ultrasound, color flow and Doppler waveform of the postmenopausal adnexal mass. Obstet. Gynecol., 80: 917-921. http://cat.inist.fr/?aModele $=$ afficheN\&cpsidt $=4553$ 993

13. Kupfer, M.C., S.R. Schwimer and J. Lebovic, 1992. Transvaginal sonographic appearance of endometriomata: Spectrum of findings. J. Ultrasound Med., 11: 129-133. http://www.jultrasoundmed.org/cgi/content/abstrac t/11/4/129

14. Coleman, B.G., P.H. Arger and C.B. Mulhern Jr., 1979. Endometriosis: Clinical and ultrasonic correlation. Am. J. Roentgenol., 132: 747-749. http://www.ajronline.org/cgi/content/abstract/132/5 1747

15. Jain, K.A., D.L. Friedman, T.W. Pettinger, R. Alagappan, R.B. Jeffrey Jr. and F.G. Sommer, 1993. Adnexal masses: Comparison of specificity of endovaginal US and pelvic MR imaging. Radiology, 186: 697-704. http://radiology.rsna.org/content/186/3/697.abstract

16. Aleem, F., J. Pennisi, K. Zeitoun and M. Predanic, 1995. The role of color Doppler in diagnosis of endometriomas. Ultrasound Obstet. Gynecol., 5: 51-54. http://www3.interscience.wiley.com/journal/10302 0185/abstract?CRETRY $=1 \&$ SRETRY $=0$
17. Pascual, M.A., F. Tresserra, L. Lopez-Marin, A. Ubeda, P.J. Grases and S. Dexeus, 2000. Role of color Doppler ultrasonography in the diagnosis of endometriotic cyst. J. Ultrasound Med., 19: 695-699. http://www.jultrasoundmed.org/cgi/content/abstrac t/19/10/695

18. Kurjak, A., H. Shalan, S. Kupesic, M. Predanic, I. Zalud, B. Breyer and S. Jukic, 1993. Transvaginal color Doppler sonography in the assessment of pelvic tumor vascularity. Ultrasound Obstet. Gynecol., 3: 137-154.

http://www3.interscience.wiley.com/journal/10352 7018/abstract

19. Nezhat, F.R., C.H. Nezhat, S. Borhan and C.R. Nezhat, 1994. Is hormonal suppression efficacious in treating functional ovarian cysts? J. Am. Assoc. Gynecol. Laparosc., 1: S26. http://www.ncbi.nlm.nih.gov/pubmed/9073730

20. Alcazar, J.L., C. Laparte, M. Jurado and G. Lopez-Garcia, 1997. The role of transvaginal ultrasonography combined with color velocity imaging and pulsed Doppler in the diagnosis of endometrioma. Fertil. Steril., 67: 487-491. http://journals.indexcopernicus.com/abstracted.php ?icid=244115

21. Kurjak, A. and S. Kupesic, 1994. Scoring system for prediction of ovarian endometriosis based on transvaginal color and pulsed Doppler sonography. Fertil. Steril., 62: 81-88. http://cat.inist.fr/?aModele $=$ afficheN\&cpsidt $=4178$ 980

22. Chapron, C., J.B. Dubuisson, X. Fritel and D. Rambaud, 1996. Diagnosis and management of organic ovarian cysts: Indications and procedures for laparoscopy. Hum. Reprod. Update, 2: 435-446. http://humupd.oxfordjournals.org/cgi/content/abstr act/2/5/435 